\title{
Wheat Landraces Are Better Qualified as Potential Gene Pools at Ultraspaced rather than Densely Grown Conditions
}

\author{
Elissavet G. Ninou, ${ }^{1}$ Ioannis G. Mylonas, ${ }^{1}$ Athanasios Tsivelikas, ${ }^{2,3}$ Parthenopi Ralli, ${ }^{3}$ \\ Christos Dordas, ${ }^{1}$ and Ioannis S. Tokatlidis ${ }^{4}$ \\ ${ }^{1}$ School of Agriculture, Aristotle University of Thessaloniki, 54124 Thessaloniki, Greece \\ ${ }^{2}$ International Centre for Agricultural Research in the Dry Areas, Genetic Resources Section, BP 435, Menzah 1, 1004 Tunis, Tunisia \\ ${ }^{3}$ Hellenic Agricultural Organization-DEMETER, Agricultural Research Center of Northern Greece, Thermi, \\ 57001 Thessaloniki, Greece \\ ${ }^{4}$ Department of Agricultural Development, Democritus University of Thrace, 68200 Orestiada, Greece
}

Correspondence should be addressed to Ioannis S. Tokatlidis; itokatl@agro.duth.gr

Received 20 February 2014; Accepted 15 April 2014; Published 11 May 2014

Academic Editor: Antonio M. De Ron

Copyright (C) 2014 Elissavet G. Ninou et al. This is an open access article distributed under the Creative Commons Attribution License, which permits unrestricted use, distribution, and reproduction in any medium, provided the original work is properly cited.

\begin{abstract}
The negative relationship between the yield potential of a genotype and its competitive ability may constitute an obstacle to recognize outstanding genotypes within heterogeneous populations. This issue was investigated by growing six heterogeneous wheat landraces along with a pure-line commercial cultivar under both dense and widely spaced conditions. The performance of two landraces showed a perfect match to the above relationship. Although they lagged behind the cultivar by 64 and $38 \%$ at the dense stand, the reverse was true with spaced plants where they succeeded in out-yielding the cultivar by 58 and $73 \%$, respectively. It was concluded that dense stand might undervalue a landrace as potential gene pool in order to apply single-plant selection targeting pure-line cultivars, attributable to inability of plants representing high yielding genotypes to exhibit their capacity due to competitive disadvantage. On the other side, the yield expression of individuals is optimized when density is low enough to preclude interplant competition. Therefore, the latter condition appears ideal to identify the most promising landrace for breeding and subsequently recognize the individuals representing the most outstanding genotypes.
\end{abstract}

\section{Introduction}

The growing global population set new challenges to agricultural production that should meet higher food demands by less arable land and under variable patterns of rainfall that jeopardize the successful cultivation of annual plants [1] In other words, increasing pressure is placed on agricultural systems to supply more food under unpropitious circumstances. Future climate change scenarios suggest that abiotic stress may occur at unexpected stages of plant development, thus decreasing yield consistency [2]. Global warming scenarios could reduce wheat productivity in zones where optimal temperature already exists, potentially increasing food insecurity and poverty [3]. As a consequence, breeding of new cultivars ought to play a crucial role in the days ahead in order to combat these challenges. However, in predominantly self-pollinated species like wheat, no longterm investments are attracted when farmers use their own seeds [1]. Hence, the utilization of the genetic variability of traditionally cultivated and locally adapted farmer varieties, the so-called landraces, may offer an alternative short-term channel. Such germplasms constitute valuable gene pools [4] and presumably consist of mixtures of fairly homogeneous plants offering thus the chance to immediately isolate singleplant progenies targeting pure-line cultivars.

Recently, a lot of effort has put into collecting, organizing, studying, and analyzing wheat landraces, whose potential for improved deployment and exploitation and incorporation of their positive qualities into new cultivars was explored [4]. The identification of the most promising landraces to employ breeding and build pure-line cultivars is the first crucial step in accomplishing a successful progress through 
selection. Since, a negative relationship between yielding and competitive ability has been reported [5-8], the aim of this study was to assess whether the normally used densities, that enforce intragenotype competition or the absence of competition, offer more chances to recognize the promising landraces to employ breeding.

\section{Materials and Methods}

The study pertains to six wheat landraces, plus one cultivar (cv. Simeto) as check (see Table 1). The cultivation of landraces "Nteves" and "Grinias" is reported at the beginning of 20th century [9]. These six landraces had been important varieties for wheat production in Greece till the 80 s, when acquired during the large wheat collection of the Greek Gene Bank, just before they have been replaced by modern wheat cultivars (P. Ralli, personal communication). They were tested in a three-year field experimentation as winter-type wheat (sowing time, middle of November), at the farm of the Agricultural Research Centre of Northern Greece, Hellenic Agricultural Organization-DEMETER, Thessaloniki (2008/09 and 2009/10), and at the farm of Aristotle University of Thessaloniki (2011/12). The landraces were initially evaluated at the typical farming density (TFD), that is, $400-500$ plants $\mathrm{m}^{-2}$, and under low-input regime, without fertilizers and herbicides, according to the cultivation techniques that growers are following in the area of the landrace origination. The previous crop in the field was vetch and the weed control was obtained by manual hoeing. Additionally, an evaluation under a conventional regime at the TFD was conducted, where weed control was accomplished through application of preemergent herbicide (Tribenuron methyl and diclofop methyl) and hand weeding. The basic fertilization applied at sowing was $48 \mathrm{~kg} \mathrm{ha}^{-1} \mathrm{~N}$ and $60 \mathrm{~kg} \mathrm{ha}^{-1} \mathrm{P}_{2} \mathrm{O}_{5}$ in the form of phosphate ammonium (16-200 ). Additionally, $100.5 \mathrm{~kg} \mathrm{ha}^{-1} \mathrm{~N}$ was applied in the middle of March as nitrate ammonium (33.5-0-0). Lastly, the experimentation was carried out at an ultralow density (ULD), where the fertilization and weed control were implemented according to the above conventional.

During the growing seasons of 2008/09 (low-input trial) and 2009/10 (conventional system), the six landraces and their check were sowed at a rate of $160 \mathrm{~kg} \mathrm{ha}^{-1}$ targeting the TFD of 400-500 plants $\mathrm{m}^{-2}$, along with additional 29 landraces from the same collection and 14 commercial cultivars. The experimental design was the one-factor randomized complete block (RCB), with three replications per entry. Each plot consisted of seven rows of $2 \mathrm{~m}$ long and $25 \mathrm{~cm}$ interrow distance, with the five central rows finally harvested $\left(2.5 \mathrm{~m}^{2}\right)$. Analysis of variance was conducted for yield per area and over the two regimes. During the 2011/12 season a replicated7 (R-7) honeycomb experiment was established including 70 plants per entry, with interplant distance of $100 \mathrm{~cm}$ (ULD of 1.15 plants $\mathrm{m}^{-2}$ ). Such a density was assumed to preclude any plant-to-plant interference for resources (absence of competition). Each hill was over-planted and thinned to one seedling in the middle of February, and individual plants were harvested separately. The mean yields per plant were

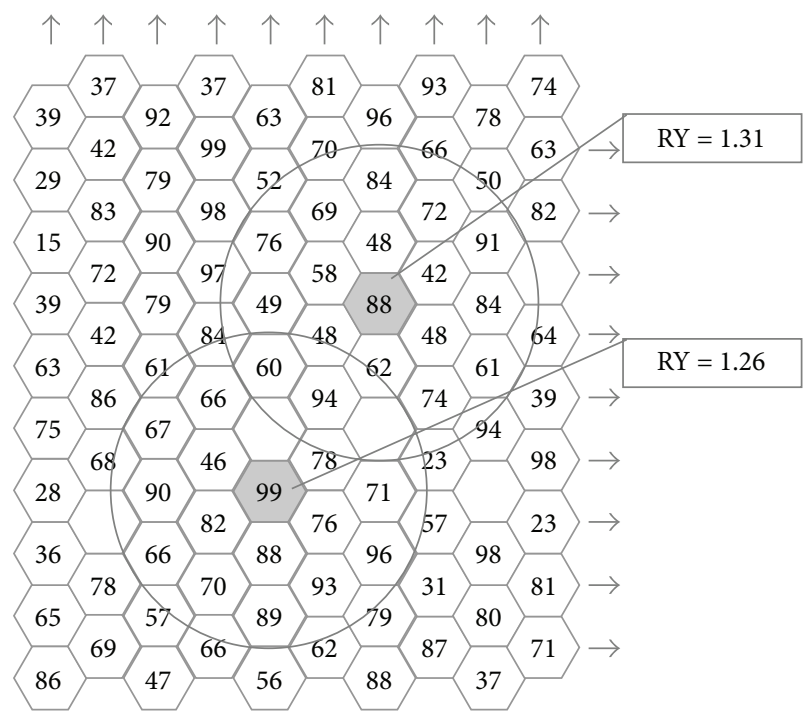

FIGURE 1: Single-plant qualification within a population allocated according to the honeycomb pattern [10]. Value of each plant is measured through its relative yield $\left(x / \bar{x}_{r}\right)$; that is, absolute yield $(x)$ of the central plant is divided by the mean yield $\left(\bar{x}_{r}\right)$ of all the plants included in the circle of a chosen size (up to 19 plants in this hypothetical example, missing plants do not exert any effect on the condition they are positioned widely enough to exclude interplant competition). The upper central plant is granted on relative yield better than the lower central plant (1.31 versus 1.26 ), even though worse on absolute yield ( 88 versus $99 \mathrm{~g}$ ).

compared by the $t$-test for independent samples and different standard deviations. Aiming to evaluate the landraces as potential starting material for the development of new pureline cultivars, single plant selection was simulated at the ULD. The procedure qualifies each plant for relative yield, that is, the ratio of its absolute yield over the mean yield of the plants involved within a circle of chosen size the centre of which is occupied by the plant in question [10]. A hypothetical example is presented in Figure 1 using a circle size of 19 plants (18 plants surrounding the one under consideration).

\section{Results}

The analysis of variance for the two densely grown experiments revealed significant $F$ values $(P<0.001)$ for genotype grain yield. The interaction of genotype by input regime was significant, depicting different genotype response and rank in the two trials. The 50 genotypes averaged grain yield of 773$4,162 \mathrm{~kg} \mathrm{ha}^{-1}$ at the low-input field and $740-4,467 \mathrm{~kg} \mathrm{ha}^{-1}$ at the conventionally grown field. On average the landraces lagged behind the cultivars by 42 and $51 \%$, respectively. On the over season performance, the best landrace named Atsiki4 (Table 1 ) yielded slightly less than the worst commercial cultivar, that is, 2,219 versus $2,345 \mathrm{~kg} \mathrm{ha}^{-1}$.

As far as the six landraces that pertain to both density regimes are concerned, Figure 2(a) illustrates the grain yield performance at the TFD comparatively with that at the ULD. At the TFD and over the input regime, all the six landraces 
TABLE 1: Wheat (Triticum spp.) landraces and the check cultivar used.

\begin{tabular}{lcccc}
\hline Code & Name & Species & Date of acquisition & Origination \\
\hline 1 & Ntopia Heracleiou-184 & T.durum & 1982 & Heraklion/Crete \\
2 & Atsiki-4 & T. durum & 1982 & Lemnos \\
3 & Mavragani Samou & T. durum & 1983 & Samos \\
4 & Nteves-35 & T. durum & 1982 & Northwest Greece \\
5 & Zoulitsa Arkadias & T. aestivum & 1982 & Arkadia \\
6 & Grinias Zakynthou & T. aestivum & & Zakynthos \\
check & cv. Simeto & T. durum & & GAIA SEEDS S.A \\
\hline
\end{tabular}

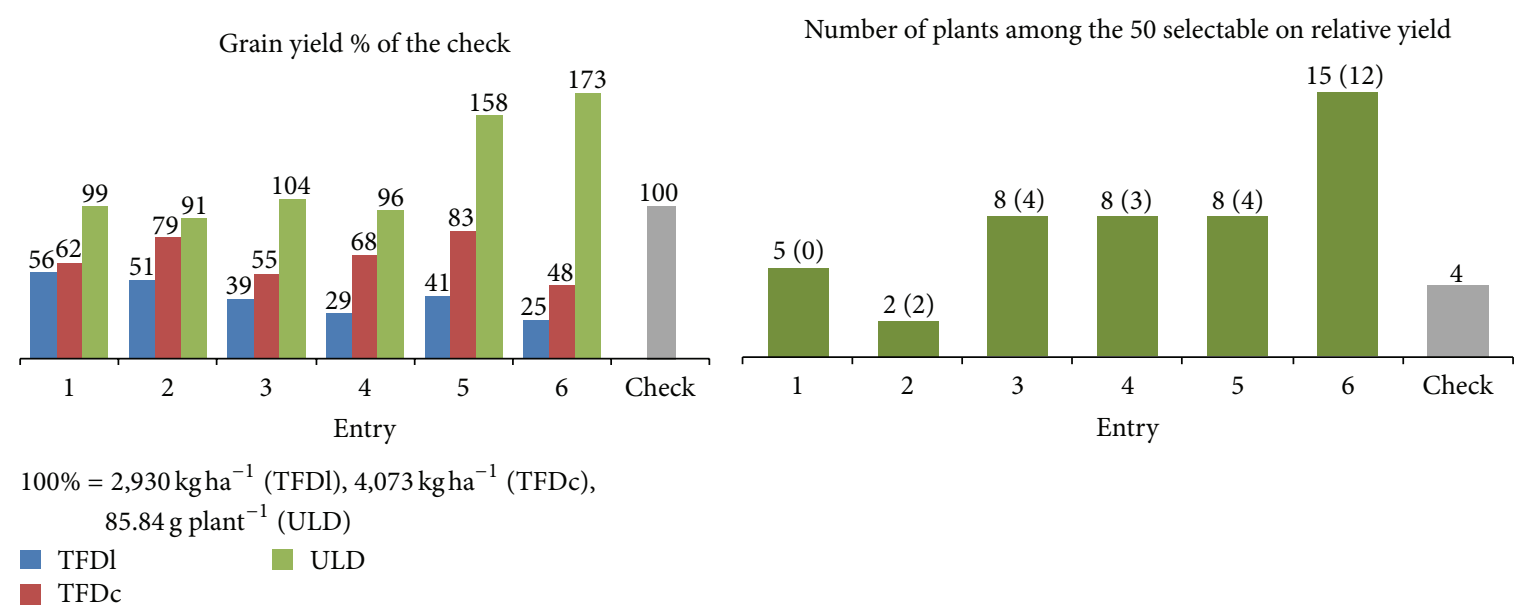

(a)

(b)

FIGURE 2: (a) Yield performance of the six landraces (1-6) and the check cultivar at the typical farming density under the low-input (TFDl) and conventional regime (TFDc), as well as at the ultralow density (ULD). (b) The number of selectable plants of each genotype on the relative yield at the ULD (in parenthesis the number of plants exceeding the highest check relative yield).

lagged behind the check significantly by 36 up to $64 \%$. However, at the ULD a different calculation was drawn. Four out of the six landraces managed to reach the $91-104 \%$ of the check and no one was significantly inferior. The landrace 5 and the poorest performing at the TFD landrace 6 succeeded in out-yielding significantly $(P<0.001)$ the check cultivar by 58 and $73 \%$, respectively.

Assuming that the 50 plants were selectable on the basis of their relative yield on a circle size of 61 , four of them belonged to the check while each landrace gave more outstanding plants, excepted for the landrace 2 (Figure 2(b)). The landrace 6 gave 15 selectable plants, followed by the landraces 3,4 , and 5 each involving 8 selectable plants. Assuming the highest check relative yield as the baseline (i.e., 1.52), half of the selectable plants exceeded this value (1.53-2.44).

\section{Discussion}

The results at the TFD could be interpreted as no landrace merits further consideration as breeding source. However, it was assumed as possible misinterpretation whether the negative relationship between genotype yield potential and competitive ability was present [5-8]. The hypothesis of negative association led to the decision that the next step should be an investigation under conditions that eliminate any essential influence of the interplant competition, that is, at the ULD. For this purpose, six landraces originating from differing Greek areas (Table 1) were chosen, that varied in yield at the TFD including the best and the worst ones, plus one of the most popular cultivars used for conventional cultivation. The reverse relevant to the check status of the two landraces coded 5 and 6 (Figure 2(a)) could be explained, if the speculation of the negative relationship between yield and competitive ability is taken into account. In essence, the ecosystems created in this study mirrored the three ones defined by Donald and Hamblin [11]. At the ULD the "isolation environment" regardless of the germplasm, whereas at the TFD the "competition environment" in case of the landraces and the "crop environment" in case of the check cultivar. At the isolation environment the widely spaced plants do not interfere for resources, and grow absolutely on individual potential and the available inputs. Therefore, competitive ability of individuals is of no importance and the condition optimizes the phenotypic expression of each genotype [10]. The competition environment comprises crowded plants of various genotypes. Within a mixture of genetically dissimilar individuals a part of genotypes may 
represent strong competitors but low yielders (Cy) at one extreme and weak competitors but high-yielders (cY) at the other [12]. In sequence of the prevailing intergenotype competition, plants share unequally the limited resources with $\mathrm{Cy}$ to have an advantage over the neighbouring $\mathrm{cY}$. Accounting for genetic competition by the acquired competition environmentally induced (i.e., uneven germination, soil heterogeneity, pathogens, and insects), the advantage of Cy over cY might strengthen [10]. In other words, large individuals are able to obtain more resources than their share and to suppress the growth of smaller individuals. Consequently, intense crowding severely restrains yielding capacity of $\mathrm{cY}$ individuals, resulting thus in poor overall performance. At the ULD instead, the cY plants fully express their high yield potential and boost the overall landrace performance. The hypothesis justifies the poor average landrace performance at the TFD and perfectly applies for the two landraces coded 5 and 6 that performed the worst at the TFD and the best at the ULD. Lastly, dense stand of the check cultivar reflects intragenotype competition with individual plants striving "equally" for the limited resources, the socalled crop environment. At the crop environment, the determinant factors are the ability of the genotype to withstand in obtaining acquired variance plus the crop management to abate the environmentally induced differences. Whether these two prerequisites are met, $c Y$ genotypes of advanced genetic background and buffering ensure top yield per area in pure stand [10]. The review of 362 wheat field studies revealed a significant positive relationship between stand uniformity and mean yield [13], implying that the stand uniformity in field crops is an important mechanism for increasing grain yield [7]. Therefore, the superior yield performance of $\mathrm{cv}$. Simeto at the TFD is attributable to its genetic homogeneity.

The hypothesis of inverse connection between yield and competitive ability is also justified by previous studies. A vetch (Vicia sativa) landrace was tested along with a cultivar at a range of six densities (1.15-25 plants $\mathrm{m}^{-2}$ ); at the highest density the cultivar significantly exceeded the landrace for grain yield (29\%) but at the lowest density the reverse was true (32\% landrace superiority) [8]. The relationship of yield potential of a genotype with its genetic competitive ability was deliberately investigated in a wheat study [5], where the top at the isolation environment genotypes was top at the crop environment as well but bottom at the competition environment, while the bottom at the isolation environment performed inversely. The results from two intercropping studies are also exceptionally informative. In the sole crop system, the top out of the 10 bean (Phaseolus vulgaris) cultivars over-yielded by $400 \%$ the bottom one; inversely, in the intercropping system with a maize (Zea mays) hybrid the latter was the top and by $27 \%$ superior over the former [14]. In another study [15], among four pea (Pisum sativum) cultivars as sole crops the best cv. Allround outyielded $150 \%$ the worst cv. Salome; however, cv. Salome accumulated significantly greater amounts of $\mathrm{N}$ in intercrops with barley (Hordeum vulgare) than the other pea cultivars and yielded 53\% higher compared to $\mathrm{cv}$. Allround.
Because of the negative association between yield and competitive ability, in the competition environment the value of a landrace as a potential gene pool on which to apply breeding may be severely underestimated. It was found that the actual value of a landrace becomes apparent only when the interplant distance is high enough to ensure absence of any plant-to-plant interference for resource utilization, so that to eliminate the confounding effects of the competitive ability and allow exceptional genotypes to be revealed [8]. Landraces 5 and 6 in the present study are strong supporters of this assertion, thanks to their superiority over the check at the ULD. In terms of the selectable plants (Figure 2(b)), the landrace 6 in particular, a priori eliminable on the ground of its performance in dense stand as poorest performing, gave almost fourfold more selectable plants. Landrace 5 likewise 3 and 4 gave double number of selectable plants compared to the check. Furthermore, the fact that half of the selectable plants exceeded the highest check relative yield shows that landraces include individual genotypes potential to evolve to high yielding pure line cultivars. Moreover, genetic gain in wheat for yield and yield components has been associated more with short- rather than tall-stemmed genotypes; thus if the latter predominate within densely grown populations recognition of the desirable short genotypes becomes uncertain [16]. Consequently, single-plant selection at the ULD appears unique to further utilize the within a landrace existing variability [18].

Breeding at ultralow density is beneficial for numerous reasons [10]. For example, aside from erasing the confounding effects of intergenotypic competition, ultralow density maximizes phenotypic expression and differentiation to facilitate selection. Under very low density, two studies in wheat managed to exploit and turn to advantage even the limited intracultivar genetic variation [5, 17]. It does not exclude good performance at high density on the presupposition that the final outcome is a pure line variety where just intra- and not intergenotypic competition prevails $[10,18]$. Indicatively, highly significant correlations $(P<0.01)$ between spaceplanted nurseries and densely seeded situations were found for a number of traits including yield [19]. Further, it might implement yield compensation components targeting low and stable interseasonally optimum population, an imperative need to bridge current gap between potential and attainable yield and promote crop sustainability and food security [18]. Evidential of the value of breeding in the absence of competition are relevant studies on other crops as well [2022]. Specifically, single plant selection under very low density within two dry bean landraces proved to be successful in obtaining sister lines that at the farming density and across a range of varying conditions performed stable and yielding significantly higher than their ancestors [20]. The procedure within a lentil (Lens culinaris) landrace was successful in development of 2 nd generation sister lines of improved health status and potentially virus-tolerant varieties [21].

Concluding, it is demonstrated that a landrace, as a potential germplasm to apply breeding, may be severely underestimated under competition conditions. Different seasons of testing the input regimes might have produced a bias; however, the magnitude of differences particularly for 
landraces 5 and 6 (Figure 2(a)) allows to infer that the actual value of a landrace becomes apparent only when plant density is low enough to eliminate any plant-to-plant interference for resource utilization and erase the confounding effects of the competitive ability. Competition implies unequal resource use where the strong competitor grows at the expense of the high yielder. However, yield gain from the former fail to compensate for the yield loss of the latter, and the outcome is low yield in overall. This statement comes in agreement with two previous studies $[7,13]$ which found it necessary to reduce intrapopulation inequality. Competition also justifies the poor performance of a landrace at the TFD; however, the landrace may comprise weak competitors potential to produce highly at pure stands. The Donald "crop" ideotype is genetically homogeneous weak competitor genotype that performs well in monoculture, but does less well when surrounded by plants of the form of the "competition" ideotype [23]. The negative relationship between yield and competitive ability also justifies possible absence of relation between spaced and densely grown plants at early segregating progenies, which may erringly lead to the conclusion that there is no relationship between spaced and densely grown plants [18]. Lastly, the absence of competition appears to be an imperative condition in order to reveal the exceptional genotypes amongst a mixture of genotypes.

\section{Conflict of Interests}

The authors declare that there is no conflict of interests regarding the publication of this paper.

\section{References}

[1] P. Stamp and R. Visser, "The twenty-first century, the century of plant breeding," Euphytica, vol. 186, pp. 585-591, 2012.

[2] D. B. Lobell, W. Schlenker, and J. Costa-Roberts, "Climate trends and global crop production since 1980," Science, vol. 333, no. 6042, pp. 616-620, 2011.

[3] R. Ortiz, K. D. Sayre, B. Govaerts et al., "Climate change: can wheat beat the heat?" Agriculture, Ecosystems and Environment, vol. 126, no. 1-2, pp. 46-58, 2008.

[4] A. C. Newton, T. Akar, J. P. Baresel et al., "Cereal landraces for sustainable agriculture. A review," Agronomy for Sustainable Development, vol. 30, no. 2, pp. 237-269, 2010.

[5] D. A. Fasoula, "Correlations between auto-, allo- and nilcompetition and their implications in plant breeding," Euphytica, vol. 50, no. 1, pp. 57-62, 1990.

[6] J. Janick, "Exploitation of heterosis: uniformity and stability", in The Genetics and Exploitation of Heterosis in Crops, J. G. Coors and S. Pandey, Eds., pp. 319-333, ASA-CSSA-SSSA, Madison, Wis, USA, 1999.

[7] X.-Y. Pan, G.-X. Wang, H.-M. Yang, and X.-P. Wei, "Effect of water deficits on within-plot variability in growth and grain yield of spring wheat in northwest China," Field Crops Research, vol. 80, no. 3, pp. 195-205, 2003.

[8] T. Chatzoglou and I. S. Tokatlidis, "Decision on germplasm choice to apply breeding within a local population of common vetch is affected by crowding," Spanish Journal of Agricultural Research, vol. 10, pp. 752-755, 2012.
[9] I. Papadakis, “Greek Types of cereals," Scientific report I, Plant Breeding Station Thessaloniki, 1929 (Greek).

[10] V. A. Fasoula and I. S. Tokatlidis, "Development of crop cultivars by honeycomb breeding," Agronomy for Sustainable Development, vol. 32, no. 1, pp. 161-180, 2012.

[11] C. M. Donald and J. Hamblin, "The biological yield and harvest index of cereal as agronomic and plant breeding criteria," Advances in Agronomy, vol. 28, pp. 361-405, 1976.

[12] D. T. Kyriakou and A. C. Fasoulas, "Effects of competition and selection pressure on yield response in winter rye (Secale cereale L.)," Euphytica, vol. 34, no. 3, pp. 883-895, 1985.

[13] S. L. Taylor, M. E. Payton, and W. R. Raun, "Relationship between mean yield, coefficient of variation, mean square error, and plot size in wheat field experiments," Communications in Soil Science and Plant Analysis, vol. 30, no. 9-10, pp. 1439-1447, 1999.

[14] M. Santalla, A. P. Rodiño, P. A. Casquero, and A. M. de Ron, "Interactions of bush bean intercropped with field and sweet maize," European Journal of Agronomy, vol. 15, no. 3, pp. 185196, 2001.

[15] H. Hauggaard-Nielsen and E. S. Jensen, "Evaluating pea and barley cultivars for complementarity in intercropping at different levels of soil N availability," Field Crops Research, vol. 72, no. 3, pp. 185-196, 2001.

[16] E. Donmez, R. G. Sears, J. P. Shroyer, and G. M. Paulsen, "Genetic gain in yield attributes of winter wheat in the Great Plains," Crop Science, vol. 41, no. 5, pp. 1412-1419, 2001.

[17] I. S. Tokatlidis, I. N. Xynias, J. T. Tsialtas, and I. I. Papadopoulos, "Single-plant selection at ultra-low density to improve stability of a bread wheat cultivar," Crop Science, vol. 46, no. 1, pp. 90-97, 2006

[18] I. S. Tokatlidis, "Addressing the yield by density interaction is a prerequisite to bridge the yield gap of rain-fed wheat," Annals of Applied Biology, 2014.

[19] K. A. Hansen, J. M. Martin, S. P. Lanning, and L. E. Talbert, "Correlation of genotype performance for agronomic and physiological traits in space-planted versus densely seeded conditions," Crop Science, vol. 45, no. 3, pp. 1023-1028, 2005.

[20] I. S. Tokatlidis, I. I. Papadopoulos, D. Baxevanos, and O. Koutita, "Genotype $\times$ environment effects on single-plant selection at low density for yield and stability in climbing dry bean populations," Crop Science, vol. 50, no. 3, pp. 775-783, 2010.

[21] A. Kargiotidou, E. Chatzivassiliou, C. Tzantarmas et al., "Selection at ultra-low density identifies plants escaping virus infection and leads towards high-performing lentil (Lens culinaris L.) varieties," Journal of Agricultural Science, 2013.

[22] D. N. Vlachostergios, A. S. Lithourgidis, and D. G. Roupakias, "Effectiveness of single-plant selection at low density under organic environment: a field study with lentil," Crop Science, vol. 51, no. 1, pp. 41-51, 2011.

[23] R. H. Sedgley, "An appraisal of the Donald ideotype after 21 years," Field Crops Research, vol. 26, no. 2, pp. 93-112, 1991. 


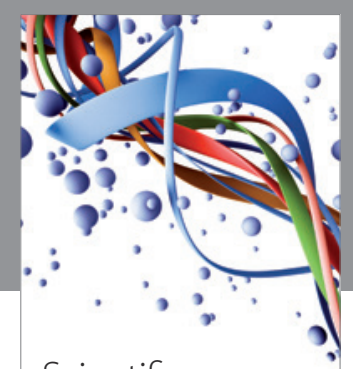

Scientifica
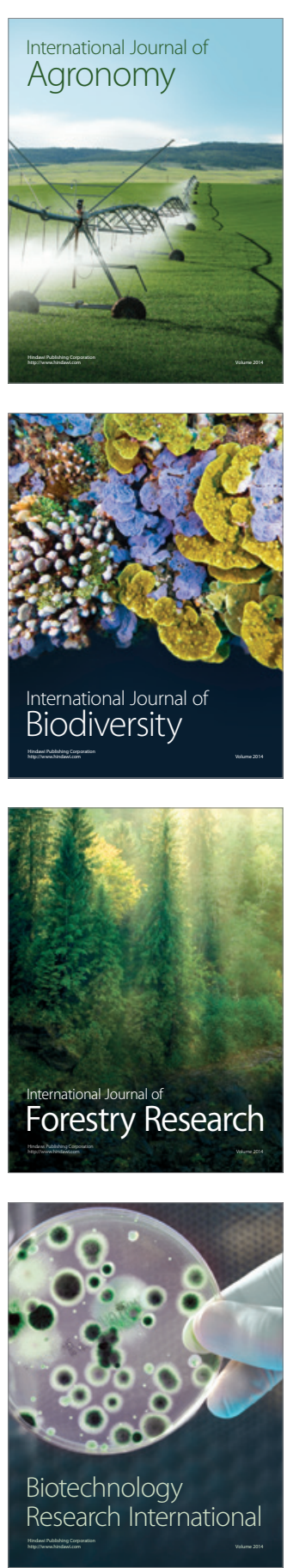
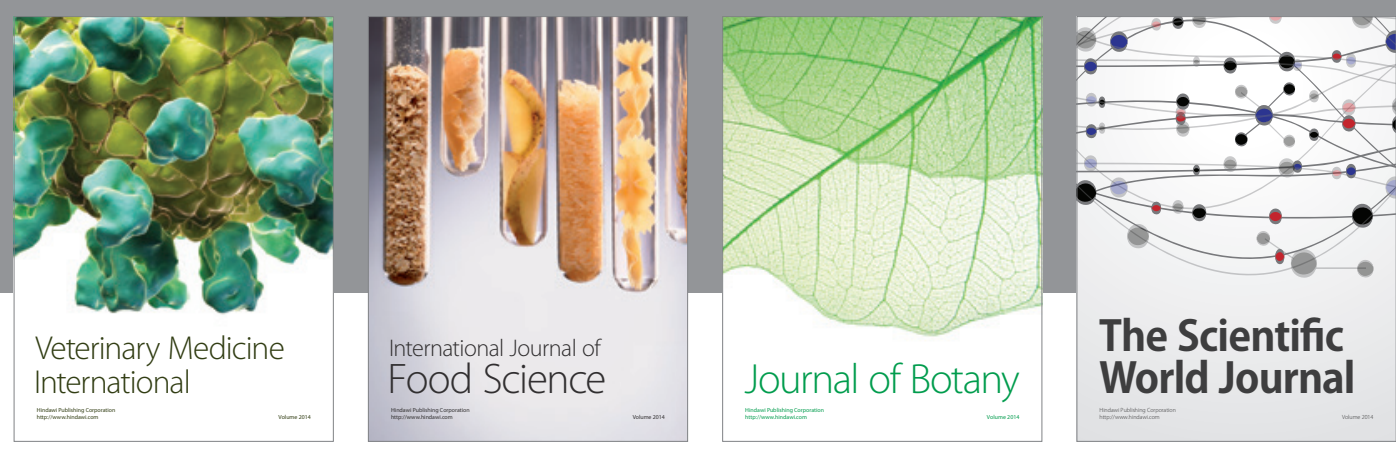

The Scientific World Journal
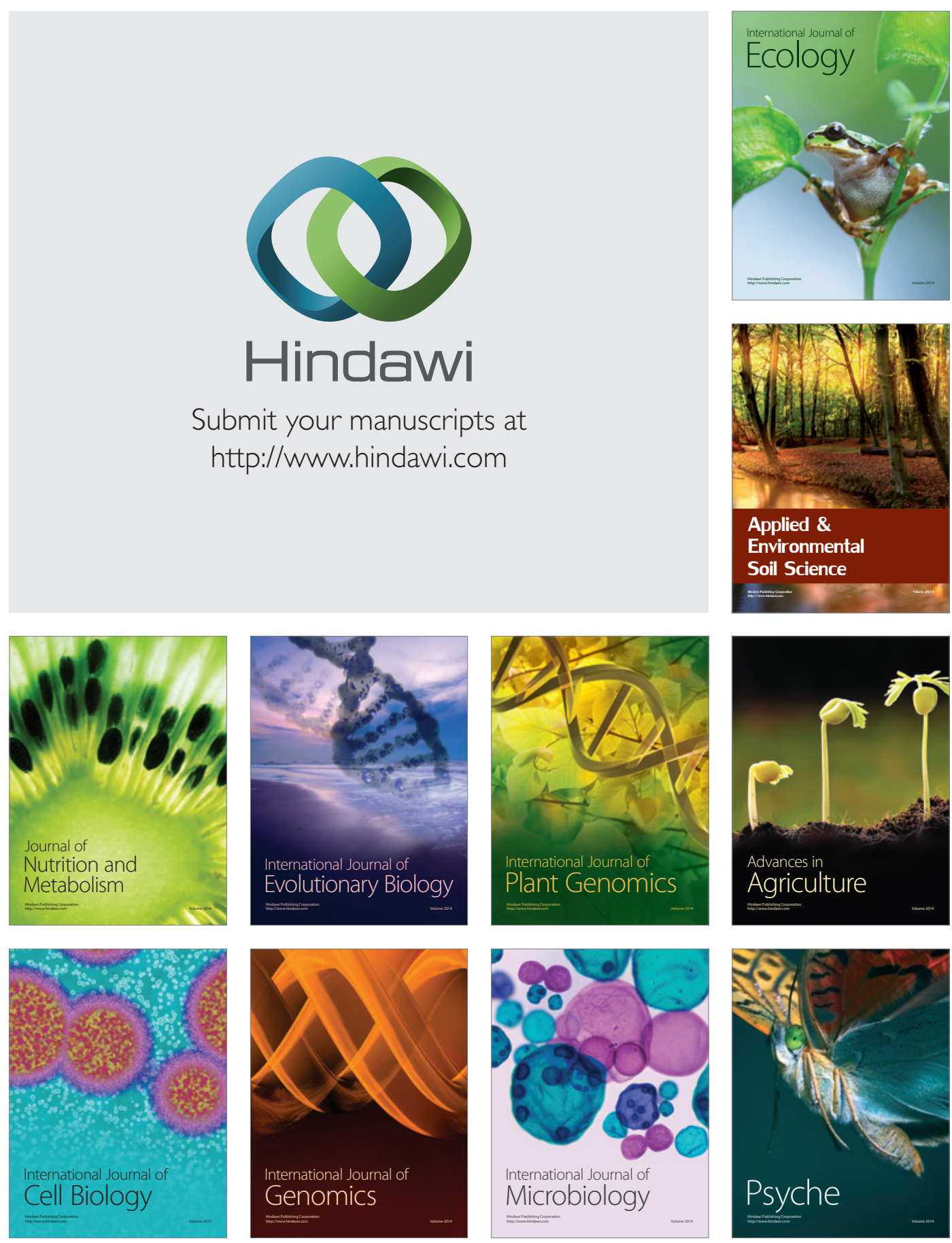